\title{
Studi Potensi Subak Tanah Yeng Sebagai Kawasan Agrowisata di Desa Sedang, Kecamatan Abiansemal, Kabupaten Badung
}

\author{
NI KOMANG DHARMA YANTII ${ }^{1}$ KOMANG ARTHAWA LILA ${ }^{2 *}$, \\ LURY SEVITA YUSIANA²
}

1Program Studi Agroekoteknologi, Fakultas Pertanian, Universitas Udayana 2Program Studi Arsitektur Pertamanan, Fakultas Pertanian, Universitas Udayana, *Email: komangarthawalila@unud.ac.id

\section{ABSTRACT \\ Tanah Yeng Subak Potential Study as an Agrotourism in Sedang Village, Abiansemal, Badung Regency}

Subak as a world heritage needs to be preserved. The issue of existence reduction of subak cause decreasing of Bali tourism attractiveness that really gives huge impact to Balinese economic-social life. One of the alternatives to prevent agricultural land into nonagricultural land is developing subak becomes agro-tourism object. Tanah Yeng Subak is one of subak that is located in Desa Sedang, Abiansemal, Badung Regency which has a big potency to be developed as an agro-tourism object. The aim of this writing is to identify the tourism potencies of Subak Tanah Yeng which can be developed become a tourism activities object. The result of the research that have been collected shows some tourism potencies of Subak Tanah Yeng, such as: the accessibility to this area is easy to reach, friendly population, regular planting rotation, cultivating diversity commodities, good maintained Subak Temple, $89,2 \%$ of the population are in productive ages, local instances that support economic matters of the population, strong and unique customs in terms of farming ceremony and Subak Tanah Yeng also provides beautiful landscape.

Keywords: subak, agro-tourism, tourism potential

\section{Pendahuluan}

Subak adalah organisasi masyarakat hukum adat, berupa perkumpulan petani pengelola air irigasi di lahan sawah, dan memiliki karakteristik sosioagraris-religius, (Windia, 2006). Keunikan budaya subak yang memiliki unsur gotong-royong dan konsep Tri Hita Karana menjadikan UNESCO mengakui subak sebagai warisan budaya dunia dalam sidang umum ke-36 di St. Petersburg, Rusia.

Disisi lain eksistensi subak mengalami penurunan akibat adanya konversi lahan pertanian ke nonpertanian. Dinas Pertanian Badung menyebutkan, bahwa sejak tahun 2008 hingga tahun 2014, sebanyak 160 ha lahan basah telah beralih fungsi menjadi pembangunan akomodasi wisata dan pemukiman warga. Lokasi dengan alih fungsi lahan terbanyak terjadi di tiga kecamatan, yaitu Kecamatan Kuta Utara mencapai 94 ha, Mengwi 33 ha, dan Abiansemal 4 ha.

Salah satu upaya yang dilakukan untuk mempertahankan keberadaan subak sebagai warisan budaya adalah melihat potensi subak sebagai objek wisata. Agrowisata adalah 
salah satu wujud untuk menempatkan sektor primer (pertanian) ke dalam sektor tersier (pariwisata). Secara umum konsep agrowisata mengandung pengertian suatu kiat atau perjalanan wisata yang dipadukan dengan aspek-aspek kegiatan pertanian (Windia dkk, 2013). Subak Tanah Yeng memiliki aktifitas pertanian yang tinggi dan SDM yang produktif. Berkaitan dengan hal tersebut penulis mencoba untuk melaksanakan studi potensi Subak Tanah Yeng sebagai kawasan agrowisata di Desa Sedang, Kecamatan Abiansemal, Kabupaten Badung. Rumusan masalah dalam penelitian ini terdiri dari 1) potensi yang dimiliki oleh Subak Tanah Yeng Desa Sedang, Kecamatan Abiansemal, Kabupaten Badung, terkait dengan pengembangan kawasan menjadi kawasan agrowisata, 2) Apakah potensi yang dimiliki oleh Subak Tanah Yeng Desa Sedang, Kecamatan Abiansemal, Kabupaten Badung layak untuk dikembangkan menjadi agrowisata. Sedangkan tujuan yang ingin dicapai dalam penelitian ini adalah 1) mengidentifikasi potensi yang dimiliki oleh Subak Tanah Yeng di Desa Sedang, Kecamatan Abiansemal, Kabupaten Badung, sehingga potensial dikembangkan sebagai kawasan agrowisata, 2) menentukan kelayakan potensi-potensi yang dimiliki oleh Subak Tanah Yeng di Desa Sedang, Kecamatan Abiansemal, Kabupaten Badung untuk dikembangkan menjadi kawasan agrowisata.

\section{METODE PENELITIAN}

\subsection{Waktu dan Tempat Penelitian}

Studi potensi yang dilakukan mulai dari tahap inventarisasi data, dilakukan pada bulan Maret-April tahun 2016. Tahap analisis dan sintesis data dilaksanakan pada bulan April-Mei 2016. Pelaksanaan studi potensi dilakukan di kawasan Subak Tanah Yeng, Desa Sedang, Kecamatan Abiansemal, Kabupaten Badung $120 \mathrm{~m}$ di atas permukaan laut (dpl).

\subsection{Alat Penelitian}

Alat yang digunakan untuk penelitian meliputi alat tulis, kamera digital, perekam suara, alat ukur (meteran), serta perangkat komputer yang digunakan untuk mengolah data.

\subsection{Jenis Data dan Sumber Data}

Pada penelitian studi potensi ini menggunakan dua jenis data, yaitu: kualitatif dan data kuantitatif. Sedangkan menurut sumber datanya, dalam penelitian ini data dikelompokkan menjadi dua bagian, yaitu: data primer dan data sekunder.

\subsection{Teknik Pengumpulan Data}

\subsubsection{Observasi}

Metode observasi dilakukan dengan pengamatan langsung terkait dengan budaya, sosial, ekonomi, fisik dan visual dari Subak Tanah Yeng serta potensi-potensi yang dimiliki oleh subak terkait dengan pengembangan kawasan menjadi kawasan agrowisata.

\subsubsection{Wawancara}

Metode wawancara dilakukan dengan mengadakan tanya jawab secara langsung terkait dengan kondisi fisik, sosial budaya dan visual dari Subak Tanah dengan pihakpihak yang dijadikan sebagai sumber kunci informan di Subak Tanah Yeng seperti: 
Pekaseh (ketua subak), Penyarikan (sekretaris), Petugas Penyuluh Lapang (PPL) Subak Tanah Yeng, dan Petani Subak Tanah Yeng.

\subsubsection{Studi Pustaka}

Pengumpulan data sekunder mencakup studi literartur, buku-buku dan hasil penelitian terdahulu. Data sekunder meliputi data geografis wilayah penelitian, data agroklimat, monografi, dan peta wilayah.

\subsection{Analisis Data}

Analisis data yang digunakan adalah analisis deskriptif dan analisis tapak. Data studi potensi yang telah terkumpul kemudian dianalisis menggunakan analisis deskriptif. Hasil dari analisis berupa kata-kata yang menggambarkan kondisi objek yang diteliti.

Selanjutnya data yang didapatkan terkait dengan potensi subak juga di analisis tapak menggunakan analisis SWOT. Analisa SWOT adalah identifikasi berbagai faktor secara sistematis untuk merumuskan sebuah strategi. Analisa SWOT didasari oleh logika yang dapat memaksimalkan kekuatan (Strengts) dan peluang (Opportunities), namun secara bersamaan dapat meminimalkan kelemahan (Weaknesses) dan ancaman (Threats). Analisa SWOT dapat ditentukan oleh kombinasi faktor internal dan eksternal.

\subsubsection{Preferensi Masyarakat}

Pengambilan data preferensi masyarakat melalui kuisioner dengan 7 buah pertanyaan. Responden yang diambil sebanyak 30 orang, meliputi : 2 orang pengurus Subak Tanah Yeng, 3 orang Pengurus Desa Sedang, 18 orang Petani di Subak Tanah Yeng, dan 7 orang masyarakat Desa Sedang. Hasil kuisioner dihitung dengan persentase.

\subsection{Batasan Penelitian}

Hasil akhir yang diharapkan, penulis mampu mengumpulkan potensi-potensi yang dimiliki Subak Tanah Yeng terkait dengan pengembangan kawasan agrowisata.

\section{Hasil dan Pembahasan}

Subak Tanah Yeng terletak pada 08034'19"LS-115014'16"BT dengan ketinggian 120m di atas permukaan laut serta memiliki topografi datar. Subak Tanah Yeng memiliki luas 136,66 Ha dengan jumlah anggota subak 372 orang yang dipimpin oleh seorang pekaseh. Komoditi yang dibudidayakan: padi (Oryza sativa), jagung (Zea mays spp.mays L), kedelai (Glycine max), labu (C. argyrosperma) dan pacar air (Impatiens balsamina L).

Kawasan Subak Tanah Yeng yang berada di Desa Sedang memiliki iklim tropis, dan curah hujan 2.000-3.000 mm per tahun dengan 106 hari hujan (Monografi Desa Sedang, 2015). Subak Tanah Yeng merupakan subak dengan irigasi teknis yang bersumber pada Bendungan Kedewatan. Kegiatan pertanian yang dilaksanakan di Subak Tanah Yeng terkait dengan Sapta Usahan Tani seperti: pengolahan tanah, pngaturan irigasi, pemupukan, pemberantasan hama dan penyakit, panen dan pemasaran.

Anggota Subak Tanah Yeng hingga saat ini tetap melaksanakan upacara terkait dengan bercocok tanam yang dilaksanakan di lingkungan subak. Ada 23 jenis upacara yang dilaksanakan seperti mendak toya, ngendag, ngurit, ngawiwit, manyi dan lain-lain. Pelaksanaan upacara ini bertujuan untuk mendapatkan hasil panen yang baik. Anggota Subak Tanah Yeng memiliki beberapa tempat suci yaitu: Pura Braban Subak Tanah Yeng, 
Pura Pangulun Empelan Munduk Dukuh, Pura Pangulun Empelan Munduk Gebang, Pura Pangulun Empelan Munduk Tegeh, Pura Laban Sindu Gianyar, Pura Kahyangan Tiga dan Sanggah Catu yang berada pada masing-masing petakan sawah petani.
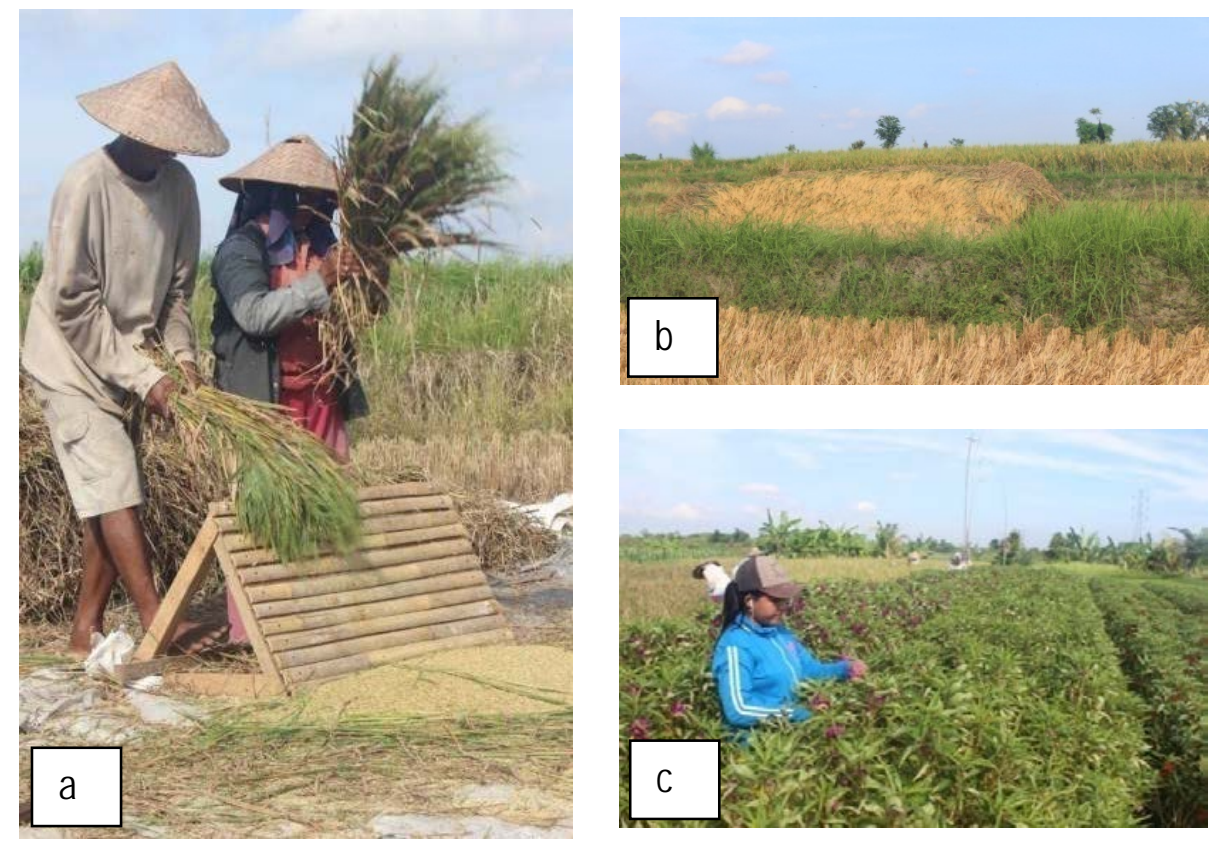

Gambar. 1

a). Perontokan Bulir Padi dengan Cara Tradisional, b). Penumpukan Padi yang Baru di Panen, c). Panen Bungan Pacar Air (Dokumentasi Pribadi, 2016).

Letak subak yang berada di Desa Sedang dengan jumlah penduduk 4.022 jiwa, dan 89,2\% (3.589 jiwa) berada pada usia produktif. Mata pencaharian utama penduduk Desa Sedang adalah buruh tani (620 jiwa) dan petani (374 jiwa).
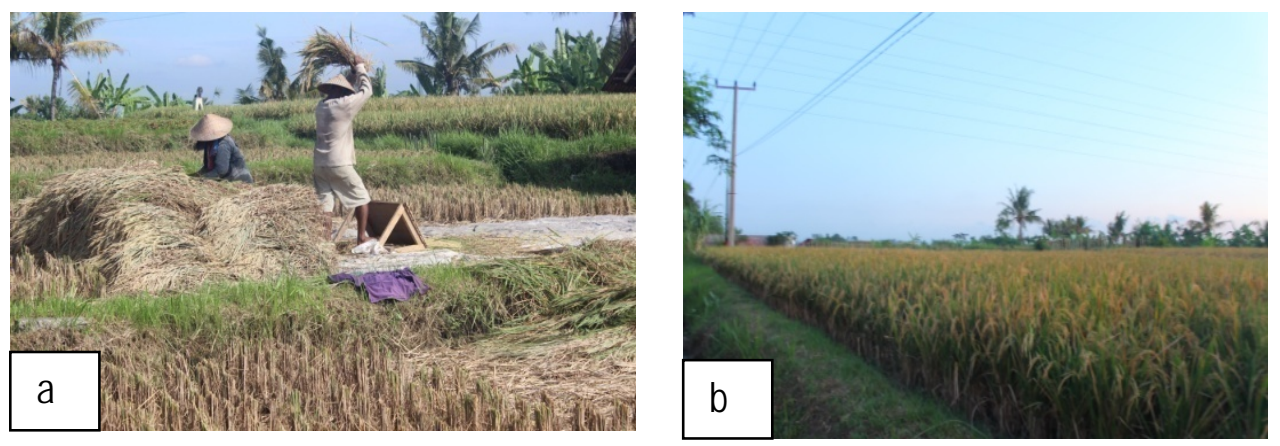

Gambar 2. a). Aktivitas Petani b). Pemandangan Subak (Dokumentasi Pribadi, 2016)

Kawasan Subak Tanah Yeng dipisahkan oleh Jalan Krasa, jalan tersebut menjadi salah satu jalur pariwisata yang menghubungkan Kabupaten Badung dan Gianyar. 
Kawasan Jalan Krasan merupakan jalur lalu lintas menuju ke Payangan, Gianyar dan ke Blahkiuh, Abiansemal. Subak Tanah Yeng memiliki lokasi yang dekat dengan Daerah Tujuan Wisata (DTW) lainnya dapat dilihat pada Tabel. 1.

Tabel 1. Jarak DTW yang Dekat dengan Subak Tanah Yeng

\begin{tabular}{ccl}
\hline No. & Nama DTW & \multicolumn{1}{c}{ Jarak (km) } \\
\hline 1. & Bali Bird Park & $\pm 5,9 \mathrm{~km}$ ke arah Timur \\
2. & Pasar Sukawati & $\pm 7,8 \mathrm{~km}$ ke timur \\
3. & Celuk & $\pm 8 \mathrm{~km}$ ke arah Tenggara \\
4. & Monkey Forest & $\pm 8,4 \mathrm{~km}$ ke arah Timur \\
5. & Goa Gajah & $\pm 12 \mathrm{~km}$ ke arah Timur \\
6. & Sangeh & $\pm 12 \mathrm{~km}$ ke arah Utara \\
7. & Bali Adventure Rafting & $\pm 12 \mathrm{~km}$ ke arah Utara \\
\hline
\end{tabular}

Sumber: Dihitung dengan Google Maps (2016)

Daerah Tujuan Wisata yang paling dekat adalah Bali Bird Park yang terketak di Singapadu, Gianyar, sedangkan DTW lainnya yang juga merupakan pusat kerajinan khas Bali yaitu Pasar Sukawati yang terletak di Sukawati, Gianyar berjarak $\pm 7,8 \mathrm{~km}$ ke timur. Untuk dapat melihat kerajinan berupa perak berjarak $\pm 8 \mathrm{~km}$ ke arah Tenggara dari Subak Tanah Yeng yaitu Celuk, Gianyar. Sedangkan Monkey Forest berjarak $\pm 8,4 \mathrm{~km}$ ke arah Timur, dan Goa Gajah, Sangeh serta Bali Adveture Rafting berjarak $\pm 12 \mathrm{~km}$ ke arah Timur dan Utara.

Bali Bird Park memiliki jumlah kunjungan 163.032 wisatawan lokal dan mancanegara setiap bulannya, Goa Gajah memiliki jumlah kunjungan 286.418 wisatawan setiap bulannya, Bali Adventure Rafting memiliki jumlah kunjungam 35.516 wisatawan mancanegara setiap bulannya, dan Sanggeh memiliki jumlah kunjungan 84.068 wisatawan lokal dan mancanegara setiap bulannya. Sedangkan Pasar Seni Sukawati memiliki jumlah kunjungan 2.000 wisatawan lokal dan mancanegara setiap harinya dan Monkey Forest sebanyak 500 wisatawan lokal dan mancanegara setiap harinya (Antara, 2011). Tingginya tingkat kunjungan menuju DTW yang dekat dengan Subak Tanah Yeng dapat dikaitkan menjadi sebuah paket perjalanan wisata di Pulau Bali. Pada Tabel 2 dapat dilihat jumlah kunjungan wisatawan ke DTW yang dekat dengan Subak.

Tabel 2. Jumlah Kunjungan Wisata ke DTW yang Dekat dengan Subak Tanah Yeng

\begin{tabular}{ccccc}
\hline No. & DTW & $\begin{array}{c}\text { Wisatawan Lokal } \\
\text { (per bulan) }\end{array}$ & $\begin{array}{c}\text { Wisatawan } \\
\text { Mancanegara (per } \\
\text { bulan) }\end{array}$ & Total \\
\hline 1. & Sangeh & 64.931 & 10.137 & 84.068 \\
2. & Goa Gajah & 43.920 & 242.498 & 286.418 \\
3. & Bali Advemture Rafting & - & 35.516 & 35.516 \\
4. & Bali Bird Park & 97.601 & 65.431 & 163.032 \\
\hline
\end{tabular}

Sumber: DISPRADA PROV.BALI (2014). 
Setelah melakukan inventarisasi data terkait dengan potensi fisik, sosial, budaya dan visual yang dimiliki oleh Subak Tanah Yeng maka potensi-potensi tersebut dapat dilihat pada Tabel 3.

Tabel 3. Analisis Tapak Potensi-Potensi Wisata di Subak Tanah Yeng

\begin{tabular}{|c|c|}
\hline \multicolumn{2}{|c|}{ FAKTOR INTERNAL } \\
\hline Kekuatan (Strength) & Kelemahan (Weakness) \\
\hline $\begin{array}{l}\text { 1. Keberadaan subak yang tetap } \\
\text { terjaga dengan adanya awig-awig, } \\
\text { perarem, bale subak, pura subak, } \\
\text { dan jineng serta upacara terkait } \\
\text { dengan bercocok tanam masih } \\
\text { dilestarikan. }\end{array}$ & $\begin{array}{l}\text { 1. Belum adanya organisasi pengelola } \\
\text { wisata } \\
\text { 2. Belum diperhatikannya industri } \\
\text { kreatif masyarakat } \\
\text { 3. Letak subak di pinggir jalan yang } \\
\text { menyulitkan untuk parkir }\end{array}$ \\
\hline $\begin{array}{l}\text { 2. Keramah tamahan masyarakat di } \\
\text { Desa Sedang }\end{array}$ & \\
\hline $\begin{array}{l}\text { 3. Di kawasan Subak Tanah Yeng } \\
\text { belum terjadi konversi lahan } \\
\text { pertanian ke non pertanian }\end{array}$ & \\
\hline $\begin{array}{l}\text { 4. Masyarakat Desa Sedang } 3.589 \\
\text { jiwa }(89,2 \%) \text { berada pada usia } \\
\text { tenaga kerja }\end{array}$ & \\
\hline $\begin{array}{l}\text { 5. Pergiliran pola tanam teratur dan } \\
\text { keragaman komoditi yang } \\
\text { dibudidayakan }\end{array}$ & \\
\hline $\begin{array}{l}\text { 6. Akesibilitas menuju subak sangat } \\
\text { mudah }\end{array}$ & \\
\hline 7. Memiliki topografi datar & \\
\hline FAKTOR & KSTERNAL \\
\hline Peluang (Opportunities) & Ancaman (Threat) \\
\hline $\begin{array}{l}\text { 1. Kawasan Subak dilindungi oleh } \\
\text { PERDA sebagai kawasan hijau } \\
\text { 2. Berada pada jalur wisata menuju } \\
\text { DTW lainnya }\end{array}$ & $\begin{array}{l}\text { 1. Kesamaan atau kemiripan } \\
\text { agrowisata dengan agrowisata } \\
\text { lainnya }\end{array}$ \\
\hline
\end{tabular}

\subsection{Kekuatan (Strength)}

Kekuatan (strength) adalah faktor internal yang dimiliki oleh Subak Tanah Yeng. Faktor internal tersebut adalah potensi-potensi yang dapat mendukung adanya pengembangan kawasan menjadi kawasan agrowisata. Berikut adalah kekuatan (strength) yang dimiliki oleh Subak Tanah Yeng: 
Keberadaan subak itu sendiri yang masih tetap terjaga dan lestari hingga saat ini dikarenakan Awig-awig, Perarem, Bale Subak, Pura Subak, dan Jineng serta upacara terkait dengan bercocok tanam masih tetap terjaga hingga saat ini sebagai peraturan yang dapat mempersatukan masyarakat tani di Subak Tanah Yeng. Revitalisasi terkait Awigawig subak melalui membedah dan menganalisis Awig-awig Subak, yang selanjutnya diperketat dengan aturan-aturan tertulis yang contextual dengan pencegahan alih fungsi lahan pertanian secara tegas (C.Kardi dan Wiasta, 2014).

Petani yang berada di Subak Tanah Yeng sebagian besar merupakan masyarakat Desa Sedang dan desa-desa di sekitarnya. Keramah tamahan adalah ciri dari masyarakat desa. Berdasarkan observasi lapang, setiap orang asing yang memasuki kawasan Subak Tanah Yeng, maka petani di sekitarnya akan memberikan senyuman dan sapa. Keramahan dapat menarik wisatawan untuk berkunjung maupun kembali berkunjung ke tempat wisata tersebut (Mentari, 2014).

Di kawasan Subak Tanah Yeng belum terjadi konversi lahan pertanian ke non pertanian hal ini dikarenakan kawasan subak dilindungi oleh PERDA yang menetapkan kawasan menjadi jalur hijau. Sehingga lahan subak yang dimiliki masih lestari.

Masyarakat Desa Sedang berjumlah 4.022 jiwa, dan 89,2\% masyarakat desa berusia tenaga kerja. Usia masyarakat desa yang produktif mempengaruhi perkembangan suatu kawasan menjadi kawasan yang berkembang. Banyaknya tenaga kerja produktif mendorong kemajuan perekoniman kawasan. Usaha-usaha yang dikembangkan akan mampu menyerap tenaga kerja produktif secara optimal, dan meningkatkan perekonomian masyarakat. Selain itu adanya pengembangan agrowisata di Desa Sedang juga dapat menekan urbanisasi dari desa ke kota. Masyarakat dengan usia produktif dapat mengandalkan agrowisata sebagai mata pencahariannya. Sumberdaya manusia adalah modal dalam usaha wisata, yang dapat diwujudkan menjadi potensi nyata dalam mewujudkan eksistensi kawasan wisata tersebut (Arjana, 2015).

Pergiliran pola tanam yang telah disepakati bersama oleh anggota Subak Tanah Yeng terbagi atas 2 kelompok. Dimasing-masing kelompok akan ada 1 bulan untuk pengistirahatan lahan, sementara lahan di kelompok yang lainnya akan tetap berproduksi. Komoditi yang dibudidayakan di Subak Tanah Yeng beragam diantaranya: padi, jagung, kedelai, labu dan pacar air. Kegiatan petani dalam berusaha tani terkait dengan pembudidyaan komoditi seperti membajak sawah, menanam padi, dan panen merupakan atraksi yang menarik untuk disaksikan oleh wisatawan (Windia, 2013).

Berdasarkan observasi lapang yang saya lakukan, akses untuk mencapai Subak Tanah Yeng sangat mudah. Hal tersebut dikarenakan Subak Tanah Yeng dilintasi oleh jalan Provinsi Badung-Gianyar yang melalui Desa Sedang dengan lebar kurang lebih empat meter. Untuk mencapai Subak Tanah Yeng, sarana transportasi yang dapat digunakan berupa angkutan pribadi. Lokasi tempat wisata harusah mudah dijangkau atau memiliki aksesibilitas yang baik mencakup, jarak maupun ketersediaan moda transportasi darat, udara, laut yang mudah dan murah (Arjana, 2015). Jarak dari Pusat Pemerintahan Kabupaten Badung menuju Subak Tanah Yeng sekitar 10 km dan 12 km dari Pusat Kota Denpasar. Subak Tanah Yeng juga dekat dengan beberapa DTW lainnya seperti Bali Bird 
Park, Celuk, Goa Gajah, Monkey Forest, Sangeh, Bali Adventure Rafting, dan Pasar Seni Sukawati.

Keberadaan subak pada topografi yang datar memudahkan untuk perencananaan sirkulasi wisata sebagai penunjang aktivitas trekking. Sepanjang mata memandang wisatawan dapat menikmati persawahan yang dataran rendah. Dataran rendah adalah kawasan yang paling ideal di muka bumi, sehingga banyak fasilitas lainnya yang didirikan di dataran rendah. Mendirikan sebuah agrowisata di dataran rendah memiliki keuntungan tersendiri yaitu dekat dengan fasilitas lainnya. (Arjana, 2015).

\subsection{Kelemahan (Weakness)}

Kelemahan (weakness) adalah faktor internal yang dimiliki oleh Subak Tanah Yeng yang dipandang perlu untuk diperhatikan dan dikembangkan untuk mendukung pengembangan kawasan subak menjadi agrowisata. Kelemahan-kelemahan yang dimiliki oleh Subak Tanah Yeng adalah sebagai berikut: Subak Tanah Yeng belum memiliki organisasi pengelola wisata. Menurut Arjana, 2015 pengelola wisata adalah salah satu unsur terpenting dalam pengembangan kawasan agrowisata. Adanya pengelola wisata bertugas untuk memanajemen segala sesuatu terkait dengan agrowisata dan pengembangannya. Untuk itu dalam pengembangan subak menjadi kawasan agrowisata dibutuhkan pengelolaan yang baik.

Keberadaan pengrajin skala rumah tangga belum banyak mendapat perhatian, dengan adanya pengembangan kawasan menjadi agrowisata diharapkan kerajinan yang dikembangkan oleh masyarakat sekitar dapat berkembang menjadi produk wisata. Menurut Damanik dan Weber (2006), kualitas produk wisata terkait dengan empat hal yaitu keunikan, autentisitas, originalitas dan keragaman. Untuk pengembangan produk wisata maka perlu diperhatikan hal-hal tersebut.

Letak subak di pinggir jalan raya yang menyulitkan untuk parkir. Jalur tersebut ramai dilalui oleh berbagai macam kendaraan dan menjadi jalur yang sangat sulit untuk berhenti memarkirkan kendaraan. Dibutuhkan pengaturan parkir yang baik saat kawasan Subak Tanah Yeng dikembangkan menjadi kawasan agrowisata. Dekat dengan kawasan subak terdapat sebuah wantilan dengan parkir yang cukup luas, maka wantilan tersebut dapat dijadikan sebagai salah satu alternatif untuk tempat parkir wisatawan. Wantilan tersebut memiliki kapasitas enam mobil untuk diparkirkan di bagian dalam wantilan, di depan wantilan memiliki kapasitas parkir untuk tiga mobil. Selain itu beberapa rumah masyarakat yang dekat dengan kawasan agrowisata juga dapat dijadikan sebagai tempat parkir mobil dikarenakan halaman rumah yang dimiliki oleh masyarakat cukup luas (dapat menampung dua sampai tiga mobil) dalam satu halam rumah rumah.

\subsection{Peluang (Opportunities)}

Peluang (opportunities) adalah faktor eksternal yang mendukung pengembangan subak menjadi kawasan agrowisata. Kawasan Subak Tanah Yeng sesuai dengan aturan PERDA Kabupaten DATI II Badung, adanya peraturan tersebut memberikan tanda bahwa kawasan subak merupakan kawasan jalur hijau, yang dilarang untuk mendirikan bangunan sesuai dengan ketentuan pada PERDA. Hal tersebut akan melindungi subak dari alih fungsi lahan. 
Subak Tanah Yeng juga memiliki jarak yang dekat dengan beberapa DTW lainnya. Jalan Krasan yang membagi Subak Tanah Yeng menjadi dua bagian merupakan jalan menuju beberapa DTW lainnya seperti Sangeh, Goa Gajah, Bali Bird Park, Monkey Forest, Bali Adventure Rafting, Celuk, dan Pasar Seni Sukawati. Disamping itu adanya akses yang saling berhungan ini akan dapat menciptakan paket wisata yang terkait antara satu sama lain dan didukung pula dengan tingginya tingkat kunjungan wisatawan ke DTW yang dekat dengan subak.

\subsection{Ancaman (Threat)}

Ancaman (threat) merupakan faktor eksternal dari pengembangan kawasan subak menjadi kawasan agrowisata. Berikut ancaman-ancaman pengengembangan Subak Tanah Yeng menjadi kawasan agrowisata.

Pengembangan kawasan subak menjadi kawasan agrowisata sudah memiliki beberap kompetitor salah satunya adalah Ekowisata Subak Sembung, Subak Anggabaya dan Desa Wisata Kertalangun. Pemandangan yang ditawarkan pada ketiga objek ini tidak jauh berbeda dengan Subak Tanah Yeng. Topografi subak yang datar serta komoditi yang dibudidayakan juga hampir sama. Kesamaan agrowisata tersebut mendorong pengembangan Subak Tanah Yeng menjadi kawasan agrowisata yang harus menghadirkan sesuatu yang berbeda dari kompetitornya. Atraksi kegiatan pertanian yang ada di Subak Tanah Yeng dapat menjadi nilai tambah yang akan menarik minat wisatawan untuk menyaksikan. Selain itu kebudayaan-kebudayaan dalam berbagai upacara terkait dengan bercocok tanam juga dapat menjadikan Subak Tanah Yeng memiliki keunikan tersendiri. Subak Tanah Yeng memiliki beragam komoditi yang di budidayakan oleh petani seperti padi, jagung, kedelai, pacar air dan labu. Ancaman kompetitor dapat diatasi dengan cara mengoptimalkan kekuatan (strength) yang dimiliki oleh Subak Tanah Yeng (Darsiharjo dkk, 2016).

\section{Simpulan dan Saran}

\subsection{Simpulan}

Berdasarkan hasil penelitian studi potensi kawasan Subak Tanah Yeng sebagai kawasan agrowisata di Desa Sedang, Kecamatan Abiansemal, dapat disimpulkan bahwa:

1. Subak Tanah Yeng memiliki potensi agrowisata, dengan awig-awig, perarem, Pura Subak serta upacara-upacara yang terkait dengan bercocok tanam di Subak Tanah Yeng masih tetap terjaga kelestariannya hingga saat ini.

2. Subak Tanah Yeng Desa Sedang, Kecamatan Abiansemal, Kabupaten Badung layak dikembangkan menjadi kawasan agrowisata : sebagian besar masyarakatnya berada pada usia produktif, aksesibiltas menuju subak sangat mudah, dan dekat dengan objek wisata Bali Bird Park, Celuk, Goa Gajah, Sangeh, Bali Adventure Rafting, Pasar Sukawati dan Monkey Forest.

\subsection{Saran}

Berdasarkan hasil penelitian jika kawasan tersebut akan dikembangkan menjadi kawasan agrowisata maka dapat disarankan: 
1. Perlu dibentuk lembaga wisata yang akan mengelola pengembangan subak menjadi agrowisata berbasis masyarakat subak.

2. Perlu dikembangkannya usaha industri kreatif yang dapat menunjang keberadaan agrowisata.

3. Perlu dilakukan pendampingan masyarakat oleh tenaga-tenaga professional di bidang pariwisata untuk mengelola kawasan Subak Tanah Yeng menjadi agrowisata berbasi masyarakat subak.

4. Agar dilakukan penelitian lanjutan mengenai perencanaan agrowisata di Subak Tanah Yeng, Desa Sedang Kecamatan Abiansemal, Kabupaten Badung

\section{Daftar Pustaka}

Antara Bali.2011. http://www.antarabali.com/berita/17359/hujan-kunjungan-wisatawan-kemonkey-forest-berkurang. Diakses pada 1 Oktober 2016.

Arjana, I Gusti Bagus.2015. Geografi Pariwisata dan Ekonomi Kreaftif.PT Rajagrafindo Persada.Jakarta.

Biro Pusat Statistik Propinsi Bali. 2013. Bali Dalam Angka. Denpasar

Balai Penyuluhan Pertanian. 2015. BPP Kecamatan Abiansemal, Kabupaten Badung

Desa Sedang. 2015. Monografi Desa Sedang, Kecamatan Abiansemal, Kabupaten Badung.

Kardi, C dan Wiasta, I Wayan. 2014. Revitalisasi Awig-Awig Subak dan Perilaku Agribisnis Upaya Pencegahan Alih Fungsi Lhan Sawah di Pesisir Pantai Kabupaten Buleleng. Jurnal Agrimeta. Diakses 1 Oktober 2016.

Google Maps. 2016. Google Maps. Diakses pada 1 November 2016.

Mamarodia, D. Mentari, 2014. Pengembangan Agriwisata Puncak Temboan di Rurukan Satu Kecamatan Tomohon Timur. Diakses 12 Oktober 2016

Subak Tanah Yeng. 2015. Eka Likita Subak Tanah Yeng. (terjemahan)

Windia W. 2006. Transformasi Sistem Irigasi Subak Yang Berlandaskan Konsep Tri Hita Karana.Pustaka Bali Post.Denpasar.

Windia W; W.A.A Wiguna .2013. Subak Warisan Budaya Dunia.Udayana University Press.Denpasar. 